\title{
Stakeholder Status And The Effects On Product Usability
}

Sondra Ashmore, IBM Corporation, USA

Nicole Forsgren Velasquez, Utah State University, USA

\begin{abstract}
Organizations dedicate considerable resources to developing software tools and often utilize usability studies to improve their products. Unfortunately, usability studies can be costly and some companies are using internal employees as participants in an effort to improve their product while controlling costs. However, the effects of using internal employees on usability study requirement identification and implementation is not yet understood.
\end{abstract}

This field research was conducted at a Fortune 100 Company and investigates the relationship between participants' organizational status and the implementation of usability requirements they identify for an Enterprise Storage Resource Management product. A theoretical model based on status characteristics theory is proposed. Regression analysis suggests that organizational status is a significant indicator of the likelihood of usability study requirement implementation. Organizational status of an individual should be carefully considered when soliciting product feedback.

Keywords: Usability Testing; Product Requirements; Organizational Status; Status Characteristics

\section{INTRODUCTION}

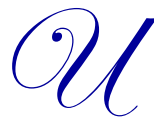

sability is a key element of human-computer interaction (HCI) (e.g., Nielsen, 1993) and is an important aspect in the successful design of any system (Shneiderman, 1980). Concerned with the ease of using a particular system to perform a particular task (Lee, 2001), usability is context-dependent (Newman \& Taylor, 1999) and is formed by the interaction of users, their work, and the tools they use to accomplish their work (Naur, 2007). The practice of creating more usable products and incorporating usability testing first emerged in the 1980's as computers started making the shift from mainframe terminals to personal computers (Nielsen, 1993). The emergence of object-oriented computing and Graphical User Interfaces (GUIs) from companies such as Xerox, Apple, and Microsoft, introduced a unique opportunity to focus on the design of a computer system rather than just the functionality of the software (Cooper, 1995). Businesses developing computer systems and software gravitated to the idea of creating usable products because it increases sales and market share, improves customer satisfaction, and boosts profitability while decreasing training and support costs and development schedules (Rosenberg, 2004).

Research has shown that usability concepts are important to include throughout the systems design process (Gould \& Lewis, 1985; Park, 1928). In addition to including usability guidelines in the early design of systems (e.g., US Department of Health and Human Services, 2006), conducting usability studies provides a better understanding of the user experience and highlights the system's strengths and weaknesses (Dumas \& Redish, 1993; Nielsen, 1993). Although usability testing has traditionally focused on end users or customers as participants (Dumas \& Redish, 1993; Hix \& Hartson, 1993; Stone, Jarrett, Woodroffe, \& Minocha, 2005), the use of actual end users in usability studies is not always practical because of the associated costs (e.g., travel, participation stipends), scheduling constraints, and confidentiality concerns (Nielsen, 1993). Thus, limited budgets and aggressive development schedules are forcing companies to look at alternative options and methodologies for usability testing (Janice et al., 2002; Rosenbaum, Rohn, \& Humburg, 2000). 
One alternative involves the selection of internal employees as usability study participants (Smilowitz, Darnell, \& Benson, 1994). The use of internal employees can reduce study costs, minimize scheduling conflicts, and reduce confidentiality implications. The rise of agile software development has also encouraged the use of stakeholder feedback sessions, which often include both internal employees as well as target customers. Stakeholder feedback sessions are typically held after each development iteration, or sprint. While criteria for evaluating which stakeholders are appropriate for a stakeholder feedback session (Power, 2010) and stakeholder goals (Sen \& Hemachandran, 2010) have been investigated, the employees' status in the organization has yet to be investigated for either of these situations.

This paper focuses on usability studies of a software program and the use of internal employees as study participants. More specifically, the impact of the organizational status of the internal study participants on requirement implementation is investigated.

\section{BACKGROUND}

Over the years, data management has advanced from early systems of manual paper tracking to complex systems that automate the processes required to store and track rich data types (Gray, 1996). This data is often housed in a complex infrastructure comprised of dozens, if not hundreds, of hardware and software components (Morris \& Truskowski, 2003). The administration of the architecture of hardware and software used to store, track, and maintain an organization's data is referred to as storage management and is a key responsibility of system administrators (Barrett et al., 2004).

Storage management software was introduced in the 1970's by IBM (Gelb, 1989) and others (e.g., Toigo, 2008) in an effort to ease the difficulty of managing complex storage networks. Early storage management software offered policy-based allocation and data management on mainframes (Gelb, 1989; Toigo, 2008), providing sysadmins with basic storage management automation capabilities. Storage management software has since evolved to include more intelligent management capabilities that provide a sysadmin with a consolidated view of their environment (e.g., storage, switches, and fabric), disaster recovery prevention policies, and future planning. This new generation of storage software is called storage resource management (SRM) (Hart \& Peterson, 2001).

SRM products are designed to make the management of complex storage environments easier and more usable in an effort to achieve three goals: reduce IT staff, use storage more efficiently, and ultimately reduce IT costs for companies (Hart \& Peterson, 2001). These goals depend on not only the basic functionality of the software, but also the usability of the product. Recent research has highlighted the importance of usability studies for products catering to sysadmins (e.g., Barrett, Chen, \& Maglio, 2003; Barrett et al., 2004; Velasquez \& Weisband, 2008), and as a sysadmin tool, the importance of usability studies for SRM tools are clearly important. Recent research in this area, however, has not directly addressed the selection of participants for these kinds of usability studies.

The context of this study is the work of system administrators, hereafter referred to as sysadmins. System administration includes maintaining, troubleshooting, installing and configuring large-scale, complex computing environments comprised of multiple components (e.g., web servers, attached storage, application servers) housed on hundreds of servers running multiple operating systems (Barrett et al., 2004). Furthermore, these complex infrastructures often require 24/7 availability (Anderson, 2002) and must be managed nearly flawlessly due to the associated costs of downtime and data loss (Patterson et al., 2002). These system characteristics' (e.g., size and complexity) and management requirements (e.g., high availability, high reliability) make usability particularly important for the tools used in system administration (Barrett et al., 2003; Barrett et al., 2004; Haber \& Bailey, 2007).

\section{THEORETICAL FRAMEWORK AND HYPOTHESIS}

Usability testing has traditionally focused on end users or customers as participants (Dumas \& Redish, 1993; Hix \& Hartson, 1993; Neilsen, 2009; Stone et al., 2005). Recent studies involving sysadmins have similarly used actual or potential end users as usability test subjects (e.g., Barrett et al., 2003; Barrett et al., 2004; Velasquez 
\& Weisband, 2008). Due to cost limitations, participant availability, and geographic location, the use of actual end users as usability subjects may not always be possible. Furthermore, recent research has found that close and regular cooperation between the development team and customers does not always guarantee a usable product (Jokela \& Abrahamsson, 2004).

Usability research and development processes have, in turn, focused on using internal employees for cost savings, solidifying employee buy-in for requirements, and encouraging creative thinking by understanding the customers point of view (Dorr, Adam, Eisenbarth, \& Ehresmann, 2008; Rainer, Hall, \& Baddoo, 2003). One method to achieve buy-in from development team members and management is to involve them in the process. By involving team members in the usability tests, the value of the product is observed, often leading the observers to want to contribute to the activity (Hornecker, Marshall, \& Rogers, 2007).

An employee's role in an organization gives them unique access to certain types of information (Ibarra \& Andrews, 1993), which can provide insight an external participant may not have. For example, a service representative may be particularly watchful of common usability complaints they get from customers, such as difficulty with installing the product. Furthermore, the availability of different types of internal employees (e.g., layout designers, programmers, etc.) provides the benefit of multiple perspectives. Research has shown that while using internal employees from different backgrounds may provide different insights into the usability of the product (Ibarra \& Andrews, 1993), studies have not yet examined the impact of organizational status of the internal subjects used.

Park (1928) defines status as a social interaction in which one individual classifies and reacts toward another individual based on age, sex, race, or social type. Status characteristics theory (Berger, 1977) builds on this definition by stating that in a group, status is related to one's ability to perform the relevant task. It further states that when characteristics unrelated to the task contribute to status, team members will act as if these characteristics are relevant and will be given greater opportunities to perform, overrule the opinions of others, and influence others in the group (Berger, 1977).

The organizational status of management versus employee implementation is recognized in research done in low-status and high status groups. High status members of an organization are more likely to get their feedback implemented in the final product (Berger, 1977). Furthermore, using employees of varying status (e.g., executive management, middle management, and front line workers) in usability studies is important because they will likely place value on different criteria. Executive management are more likely to value the worth of a system (e.g., how much the system may save a user, whether it be time or money) while front line workers are more likely to value the merit of a system (e.g., how usable the system is), and middle management is likely to consider both perspectives (Brown, Massey, \& Boling, 2005). Therefore, the use of a range of employees from front line workers to executives as usability study participants may increase the requirements discovered during a usability study, which is a goal of usability studies (Nielsen, 1993).

Once usability requirements are generated, usability research recommends that a requirements document be produced at the end of the study (Radle \& Young, 2001). However, usability recommendations rarely discuss how these requirements are implemented into the product. Organizations that use an agile methodology have started to include usability requirements in their product backlog, and the product manager works with the cross-functional development team to prioritize requirements in the backlog (Sen \& Hemachandran, 2010). The status of the product manager can vary greatly depending on the organization. Usability research has also focused on the types of usability activities that are the most successful in impacting corporate decision-making, such as focus groups and heuristic evaluations (Rosenbaum et al., 2000), but does not specifically look at the characteristics of the usability participants; namely, organizational status. A study done Bias and Reitmeyer (1995) found that buy-in from upper management was the one factor that correlated highest with product usability. One way to get buy-in from upper management is to have them participate in usability studies.

This study looks at the use of internal employees as usability study subjects and, specifically, the relationship between the organizational statuses of the usability participants and whether or not a requirement 
identified by them during the usability study was implemented. The model proposes that higher organizational status of usability test participants will increase the likelihood of requirement implementation. These relationships are supported by status characteristics theory.

\section{Status Characteristics Theory}

Status characteristics theory (SCT) focuses on the way evaluations of another's competence affect one's behavior (Berger, 1977). The theory states that differences in evaluations of individuals lead to observable differences in an interaction or interactional process. Ridgeway et al. (1994) extends this to show that differing degrees or levels of an attribute (such as organizational status) lead to differing amounts of esteem or worthiness, and the weightings of these attributes are based on cultural attitudes. In light of the current study, SCT posits that differing degrees of one's internal organizational status will lead to differing amounts of worthiness assigned to the usability requirements identified by them. The differing amounts of worthiness assigned to the requirements will be an observable outcome of the interactional process conducted by the design team. Recommended changes are judged and classified as those to be included in the current release, a future release, or not included for any release.

SCT identifies two types of status characteristics - diffuse and specific. Diffuse status characteristics create both general and specific performance expectations and include things such as gender, race, and educational level. Specific status characteristics create clear expectations about specific abilities and include mathematical ability and programming ability. Organizational status and occupation is a diffuse characteristic because each of its states (i.e., organizational levels) is assigned different general expectations regarding the cognitive ability and business savvy of the individual (Berger \& Fisek, 1970). Furthermore, this diffuse characteristic has specific performance expectations regarding the technical ability (e.g., programming ability or hardware and software architecture knowledge) of the individual. It is common that lower level employees assume that technical upper management has been promoted, in part, due to their technical abilities.

SCT states that external evaluations of status characteristics will become salient in task-related group settings (Berger \& Zelditch, 1985) and that both diffuse and specific characteristics become salient as they differentiate group members (Foddy \& Smithson, 1996; Ridgeway et al., 1994). SCT further posits that although some characteristics may be irrelevant or unrelated to the task at hand, group members will act as if the information is relevant until proven otherwise (Wagner \& Berger, 1997). In other words, although organizational status is likely unrelated to the usability of a product, the group members of the product design team will likely act as if the requirements generated by the high status participants will be more important than those generated by the lower status participants.

Research has shown that buy-in for usability testing from the development team and management is positively related to implementing usability requirements (Rosenbaum et al., 2000). Lee (2001) argues that "in an organizational setting, power is normally associated with one's position in the organization or with certain characteristics of the individual" (p. 17). Fiedler and Nealey (Fiedler \& Nealey, 1968) have found that executive management influences middle management and middle management influences group performance at the operating level. Furthermore, status characteristics theory states that high status team members are more likely to influence others in the group (Berger, 1977). This discussion leads to our hypothesis:

Hypothesis: Usability recommendations from high organizational status participants are more likely to be implemented than those recommended by low organizational status participants.

\section{METHODOLOGY}

\section{Overview}

The data used in this case study comes from four usability tests conducted by a Fortune 100 company specializing in data management software. The tests were conducted in a small computer lab and the participants were observed by a product expert and the usability test leader who were available to gather information and answer 
any questions. The product targeted for these usability tests was a storage server (beta code release) with pre-loaded storage management software typically used by medium- to enterprise-scale sysadmins to perform storage resource management (SRM). The server and software were designed and created by the Fortune 100 Company specializing in data management software with system administrator usability in mind.

Internal employees were targeted for participation in the usability study as a way to cut costs and reduce confidentiality risks. Each participant was selected and interviewed by a screener to ensure an adequate level of technical knowledge. All participants were employees of the Fortune 100 Company located throughout North America and had working knowledge of storage hardware and software, but limited in-depth knowledge or experience with the product being studied. This mix of technical knowledge (high) and familiarity with the product (low) were targeted because the focal product is often set up and configured "out of the box," with little or no previous experience with the product by the sysadmin. The participants were not selected based on their status in the organization, though their organizational status was noted during the usability study. No subjects participated in more than one usability study and studies involved either one or two people. Some participants were paired at the request of the company to reduce costs. Teams of two were used for two of the four total studies, although all participants' scores were counted separately. Teams of more than two were not used due to limited lab space. Table 1 summarizes the study participants, with organizational status anchored on level $1=$ entry level and level $7=$ vice president.

At the beginning of each study, the participants were given a brief introduction of the product, which lasted 10-15 minutes. Following the product introduction, the participants were asked to completely set up the server and software package, which is typically required during a new system delivery. The full usability test included physical set-up (physically removing the product from its packaging and connecting the required cables), software installation, and advanced configuration of the server. Participants were provided a screwdriver, all product documentation, and any settings or passwords needed to complete the installation and configuration. The product expert provided help if the participant felt that they could no longer proceed because something was confusing or inaccurate.

Table 1: Participant Summary

\begin{tabular}{|l|c|c|l|}
\hline Subject & Title & $\begin{array}{c}\text { Status } \\
\text { Level }\end{array}$ & \multicolumn{1}{c|}{ Background } \\
\hline 1 & Customer Support & 1 & Strong technical background and works in product support. \\
\hline 2 & Program Manager & 3 & $\begin{array}{l}\text { Familiar with product architecture and responsible for quality standards, but } \\
\text { with no prior hands-on use of product. }\end{array}$ \\
\hline 3 & Market Manager & 3 & Very familiar with competitors' products and provides product guidance. \\
\hline 4 & Portfolio Manager & 5 & $\begin{array}{l}\text { Extensive management and project management experience, but with little } \\
\text { system administration experience. }\end{array}$ \\
\hline 5 & $\begin{array}{c}\text { Development } \\
\text { Director }\end{array}$ & 6 & $\begin{array}{l}\text { Extensive experience with company, but less than five years as executive. } \\
\text { Approves quality certification for the product. }\end{array}$ \\
\hline 6 & Development VP & 7 & $\begin{array}{l}\text { Over 25 years experience at company, with executive roles in several areas. } \\
\text { Approves quality certification for the product. }\end{array}$ \\
\hline
\end{tabular}

Throughout the usability test, the participants interacted with both hardware and software components, which employed both graphical user interfaces (GUIs) and command line interfaces (CLIs). Initial tasks involved physically placing and laying out the hardware server and cables, installing them in a rack, and networking the server to external storage. The participant proceeded by configuring the pre-loaded operating system, which was a GUI. Next, the participant configured the agent that allowed for communication between the server and the external storage device. This process used CLI and required basic system administration knowledge, such as acquiring an IP address. Once communication between the server and external storage (via the agent) was confirmed, configuration of the proprietary storage resource management software was done using a GUI.

Feedback, comments, and observations were documented for each test and the participants were able to review the notes and make modifications if they felt any of the information was misrepresented or missing. The resulting list of usability issues was written up as product requirements and given to the product development team. 
The development team decided if the recommended requirements would be included in the current release, a future release, or not included for any release. These decisions were based on the sizing for implementation, likelihood of introducing defects into the product, and reported value to the customer. Although the organizational status of the usability participant was not officially part of the evaluation criteria, the development team was aware of the organizational status of the usability participants. Final approval by the executive team was required prior to the release of the product. Subjects five and six had approval authority.

\section{Variables}

Two constructs were used to measure the proposed research model - organizational status of the participant and requirement implementation. An explanation of these variables and how they were operationalized in this study are discussed below.

Organizational status of the participant is identified as a diffuse status characteristic and, in this study, was defined as the employee's rank in the Fortune 100 Company. Because the organizational status was easily discernable for each participant, the Company's internal classification was used. Each participant's status was assigned a value based on their current job rank in the organization, with $1=$ entry level and $7=$ vice president. Any additional status characteristics beyond internal job level, such as "team lead" or "product lead," were not included in the ranking of participants because these characteristics are not uniformly defined within the Company and would not be known to the development team. All participants had a technical background and had worked for an information technology company for two or more years.

For the purpose of this study, requirements were defined as a suggestion or recommendation specifically aimed at improving the product. Each suggested change listed during the usability study was counted as one requirement. For example, if the participant said, "I would like to see more of the installation automated. I think it can be more automated in step one and step five.", then two requirements would be logged - one for step one and one for step five. All feedback, comments, and observations were documented for each usability test and the participants were able to review the documentation and make modifications before it was handed off to the development team. The development team was aware of who suggested each requirement and the importance of each requirement as assigned by the participant (identified as high, medium, or low). The final product recommendations, or requirements, found on these modified lists were used in the study. As stated earlier, the development team decided if the recommended changes would be included in the current release, a future release, or not included for any release. Requirements to be included in the current product release or future product releases were considered "implemented" for this study, while requirements that were not to be included in any future release were considered "not implemented."

\section{RESULTS}

Each usability study was conducted and usability issues were recorded by the researcher and revised with the participants. A list of final requirements was compiled for each study, with a total of 87 requirements gathered. The distribution of the requirements is shown in Table 2.

Table 2: Usability Study Requirements Summary

\begin{tabular}{|l|c|c|c|c|}
\hline Subject & $\begin{array}{c}\text { Status } \\
\text { Level }\end{array}$ & $\begin{array}{c}\text { Number of Requirements } \\
\text { Found }\end{array}$ & $\begin{array}{c}\text { Number of Requirements } \\
\text { Implemented }\end{array}$ & $\begin{array}{c}\text { Percentage of Requirements } \\
\text { Implemented }\end{array}$ \\
\hline 1 & 1 & 21 & 8 & $38 \%$ \\
\hline 2 & 3 & 10 & 7 & $70 \%$ \\
\hline 3 & 3 & 15 & 12 & $50 \%$ \\
\hline 4 & 5 & 2 & 1 & $50 \%$ \\
\hline 5 & 6 & 24 & 21 & $60 \%$ \\
\hline 6 & 7 & 15 & 9 & $64.3 \%$ \\
\hline \multicolumn{2}{|c|}{ Mean } & 14.5 & 9.7 & \\
\hline
\end{tabular}


The requirements, implementation indicator, and participants' organizational status were entered into the binary logistic regression presented in Table 3. The ANOVA table for the regression is shown in Table 4. Findings show that participant status did have a significant association with the implementation of a requirement. This suggests support for the hypothesis that usability study recommendations made by high status participants are more likely to be implemented than those made by low status participants. Furthermore, the relative effect of a unit change in participant status on the expected odds of requirement implementation, which is $e^{\mathrm{B}}$, is 1.261.

Table 3: Regression on Requirements Implementation

\begin{tabular}{|l|c|c|c|c|c|}
\hline & B & Std. Error & Wald & Sig. & Exp(B) \\
\hline Status Level & 0.232 & 0.105 & 4.843 & 0.028 & 1.261 \\
\hline Constant) & -0.207 & 0.454 & 0.207 & 0.649 & 0.813 \\
\hline Cox \& Snell $\mathrm{R}^{2}=.057$ & \multicolumn{5}{|l}{} \\
\hline
\end{tabular}

Table 4: ANOVA on Requirements Implementation

\begin{tabular}{|l|c|c|c|c|c|}
\hline & Sum of Squares & df & Mean Square & F. & Sig. \\
\hline Between Groups & 3.096 & 4 & .774 & 3.909 & .006 \\
\hline Within Groups & 16.237 & 82 & .198 & & \\
\hline Total & 19.333 & 86 & & & \\
\hline
\end{tabular}

To ensure that the number of requirements identified was not related to the organizational status of the usability participant, a correlation was run. No significant correlation was found. Results are shown in Table 5.

Table 5: Correlation

\begin{tabular}{|l|c|c|}
\hline & Status Level & \#Requirements \\
\hline Status Level & 1.000 & -.086 \\
\hline Sig. & & .872 \\
\hline \#Requirements & -.086 & 1.000 \\
\hline Sig. & .872 & \\
\hline
\end{tabular}

Based on the results above, our hypothesis is supported; that is, usability participant status appears to have a positive influence on the likelihood of a requirement being implemented in a future product release. Furthermore, the organizational status of the participant is not correlated with the number of requirements identified.

\section{DISCUSSION}

This case study has looked at the use of internal employees as usability study participants in the context of testing a storage resource management product used by system administrators. Usability research has had some focus on justifying the cost and time required to perform a usability study (R. Bias, 1994; Donahue, 2001; Karat, 1994; Lund, 1997; Neilsen, 2009), with the use of internal employees identified as one way to reduce or mitigate cost. Research in product development has looked at how to prioritize requirements for future products based on customer pain points, standards, marketing appeal, and quality improvement (Akao, 1990; Dorr et al., 2008; Tseng \& Jianxin Jiao, 1998; Wiegers, 1999). One way to select and prioritize requirements for inclusion in future product releases is by utilizing the findings of usability studies. This study sought to understand the intersection of internal employees as usability subjects and the selection and prioritization of product usability requirements implemented in future product releases. The positive relationship between the organizational status of internal employees used in usability studies and the selection of requirements implemented in product releases suggests that while the use of internal employees may cut costs associated with usability studies, it also influences the selection of requirements implemented.

Research has suggested that the use of internal employees can be a cost-saving option for usability testing (Dorr et al., 2008; Rainer et al., 2003), but there is little research done addressing the amount of savings a company should expect. One can assume that it is less costly to use lower level employees as usability subjects than it is to use executives based on their respective salaries. However, this study shows that usability requirements identified by executives are more likely to be implemented in future product releases, possibly minimizing the benefit gained (i.e., 
cost savings) by using lower level employees. Future work should address these trade-offs and provide ways to estimate the average savings made possible by using internal employees to help justify this approach.

These findings also extend the research findings of Power (2010) by suggesting that stakeholders with higher status should be included in stakeholder feedback sessions when an agile software development approach is being used in the organization.

One key limitation of this study is the sample size. The fact that four of the participants worked in pairs may have also played a part in the results. Some participants may be less likely to speak up during a usability study if they have a partner (Berger \& Fisek, 1970). Future studies should use a larger sample size and consistently use individual participants rather than pairs.

Although some of these limitations could be avoided in a controlled experiment, the benefits of field study research provide valuable insight. Product implementation decisions made by participants in a role-playing experiment are not under the same pressures as employees whose jobs depend on the success of products that generate multi-million dollar revenues. Furthermore, the usability participant's reputation is much more salient in existing working relationships when compared to scenarios presented to role-playing participants.

Previous research has suggested that the relative size of the company may impact the requirements generated during a usability study (Rosenberg, 2004). The participants in this study were all from a large Fortune 100 Company, which may yield different results than usability studies conducted in smaller organizations. Future research should include internal usability participants from a variety of small, medium, and large companies.

While the use of internal employees as usability participants is a cost-effective alternative and provides the opportunity for many perspectives, there may be drawbacks as well. For example, research has suggested that an evaluator effect may exist in usability tests (Jacobsen, Hertzum, \& John, 1998) which may skew any usability findings toward the background of the participant. For example, developers may attend to performance or functional aspects of the product, whereas a member of the HCI team may ignore functional errors while focusing on interface layout and aesthetics. Future research may address the types of usability requirements generated from different types of participants.

In the case of getting requirements implemented into the product, other factors, besides status of the participant, could also play a significant role. This study has indicated that higher status participants do drive more requirements in the product and perhaps they are able to help get more of the large effort requirements implemented. Future studies should also look at how quickly large requirements from low versus high status participants get implemented.

These initial findings should also serve as a caution to companies using internal employees as usability participants. While using high status employees as usability participants may result in greater usability requirements implementation, the implementation team may have a bias towards requirements suggested by high status participants rather than enhancements that would add the most value to the product. Future studies should investigate the types of requirements identified by usability participants of different statuses.

Feedback from sysadmins and hardware engineers, using the storage administration appliance after these usability studies, was collected. The respondents reported that the requirements that were implemented did significantly improve the usability and serviceability of the product. The implemented enhancements have also improved the product's reputation in the field. Evaluating the relationship between the number of requirements implemented and customer satisfaction ratings, as well as possible revenue impacts, would be interesting to include in future studies.

\section{AUTHOR INFORMATION}

Sondra Ashmore is an experienced executive leader at IBM. Areas of expertise include product management, project management and new product development for information technology offerings, with experience in 
software, hardware, cloud computing and big data solutions. She received her Master's degrees at RPI in Technical Communication and Management and her Ph.D. at Iowa State University in Human Computer Interaction. Her research focuses on the software development process, both waterfall and agile, and explores strategies to optimize the user experience. E-mail: sashmore@us.ibm.com (Corresponding author)

Nicole Forsgren Velasquez is an Assistant Professor in Management Information Systems and Accounting in the Jon M. Huntsman School of Business at Utah State University. She earned her Ph.D. in Management Information Systems and her Masters in Accounting from the University of Arizona. Her research interests include knowledge management, business analytics, accounting information systems, system administration, and data analytics methods. She holds a patent and her work has appeared in IBM Journal of Research and Development and Journal of Information Systems Education, and has been presented at international conferences. E-mail: mvelasquez@scu.edu

\section{REFERENCES}

1. Akao, Y. (1990). Quality function deployment: integrating customer requirements into product design. Cambridge, Mass.: Productivity Press.

2. Anderson, E. (2002). Researching System Administration. (PhD), University of California at Berkeley, Berkeley, CA. Retrieved from http://www.ncbi.nlm.nih.gov/entrez/query.fcgi?db=pubmed\&cmd=Retrieve\&dopt=AbstractPlus\&list_uids= 13221233909745268030related:PjW3GjFCe7cJ

3. Barrett, R., Chen, Y. Y. M., \& Maglio, P. (2003). System Administrators are Users, Too: Designing Workspaces for Managing Internet-Scale Systems (Workshop). Paper presented at the Conference on Human Factors in Computing Systems (CHI' 03), Ft. Lauderdale, FL, USA. http://www.ncbi.nlm.nih.gov/entrez/query.fcgi?db=pubmed\&cmd=Retrieve\&dopt=AbstractPlus\&list_uids= 17552411493016900908related:LJXBmEGxlvMJ

4. $\quad$ Barrett, R., Kandogan, E., Maglio, P., Haber, E., Takayama, L., \& Prabaker, M. (2004, Nov 6-10 2004). Field Studies of Computer System Administrators: Analysis of System Management Tools and Practices. Paper presented at the ACM Conference on Computer Supported Cooperative Work (CSCW '04), Chicago, IL, USA.

5. Berger, Joseph. (1977). Status characteristics and social interaction : an expectation-states approach. New York: Elsevier Scientific Pub. Co.

6. Berger, Joseph, \& Fisek, M.H. (1970). Consistent and Inconsistent Status Characteristics and the Determination of Power and Prestige Orders. Sociometry, 33(287-304).

7. Berger, Joseph, \& Zelditch, M. (1985). Status, Rewards, and Influence. San Francisco: Jossey-Bass.

8. Bias, Randolph. (1994). Cost justifying usability. Boston u.a.: Academic Pr.

9. Bias, Randolph G., \& Reitmeyer, Peter B. (1995). Usability support inside and out. Interactions, 2(2), 2932. doi: http://doi.acm.org/10.1145/205350.205355

10. Brown, J., Massey, A., \& Boling, E. (2005). Evaluation of Knowledge Management Systems: Insights from the Study of a Technical Support Knowledge Base. Knowledge Management Research \& Practice, 3(2), 49-59.

11. Cooper, Alan. (1995). About Face: The essentials of user interface design. Foster City, CA: IDG Books Worldwide.

12. Donahue, George M. (2001). Usability and the Bottom Line. IEEE Softw., 18(1), 31-37. doi: http://dx.doi.org/10.1109/52.903161

13. Dorr, J., Adam, S., Eisenbarth, M., \& Ehresmann, M. (2008). Implementing Requirements Engineering Processes: Using Cooperative Self-Assessment and Improvement. IEEE SOFTWARE, 25(3), 71-77.

14. Dumas, Joseph S., \& Redish, Janice. (1993). A practical guide to usability testing. Norwood, N.J.: Ablex Pub. Corp.

15. Fiedler, FE, \& Nealey, SM. (1968). Leadership functions of middle managers. Psychological bulletin, 70(5), 313-329.

16. Foddy, M., \& Smithson, M. (1996). Relative Ability, Paths of Relevance, and Influence in Task-Oriented Groups. Social Psychology Quarterly, 59, 140-153.

17. Gelb, J. (1989). System-Managed Storage. IBM Systems Journal, 28(1), 77-103. 
18. Gould, J., \& Lewis, C. (1985). Designing for Usability: Key Principles and What Designers Think. Communications of the ACM, 28(3), 300-311.

19. Gray, J. (1996). Evolution of Data Management. IEEE Computer, 29(10), 38-46.

20. Haber, E., \& Bailey, J. (2007, Mar 30-31, 2007). Design Guidelines for System Administration Tools Developed Through Ethnographic Field Studies. Paper presented at the Computer-Human Interaction for the Management of Information Technology (CHIMIT '07), Cambridge, MA, USA.

21. Hart, L., \& Peterson, M. (2001). Storage Resource Management. IN.fusion.

22. Hix, Deborah, \& Hartson, H. Rex. (1993). Developing user interfaces: ensuring usability through product \& process. New York: J. Wiley.

23. Hornecker, Eva, Marshall, Paul, \& Rogers, Yvonne. (2007). From entry to access: how shareability comes about. Paper presented at the Proceedings of the 2007 conference on Designing pleasurable products and interfaces, Helsinki, Finland.

24. Ibarra, Herminia, \& Andrews, Steven B. (1993). Power, Social Influence, and Sense Making: Effects of Network Centrality and Proximity on Employee Perceptions. Administrative Science Quarterly, 38(2), 277303.

25. Jacobsen, N.E., Hertzum, M., \& John, B.E. (1998). The evaluator effect in usability tests. Paper presented at the CHI 98 conference summary on Human factors in computing systems, Los Angeles, California, United States.

26. Janice, A.R., Jared, S., Mayuresh, E., Sanjay, K., Michael, W., \& R., Janice. (2002). Usability in Practice: Alternatives to Formative Evaluations-Evolution and Revolution. Paper presented at the CHI '02 Extended Abstracts on Human Factors in Computing Systems, Minneapolis, MN.

27. Jokela, T., \& Abrahamsson, P. (2004). Usability assessment of an extreme programming project: Close cooperation with the customer does not equal to good usability. Paper presented at the 5th International Conference, PROFES '04.

28. Karat, C.-M. (1994). A business case approach to usability cost justification. Cost-justifying usability (pp. 45-70): Academic Press, Inc.

29. Lee, David R. (2001). An Assessment of Influence Tactics Used by Project Managers. Engineering Management Journal, 13(2), 16-25.

30. Lund, A.M. (1997). Another approach to justifying the cost of usability. Interactions, 4(3), 48-56. doi: http://doi.acm.org/10.1145/255392.255403

31. Morris, R., \& Truskowski, B. (2003). The Evolution of Storage Systems. IBM Systems Journal, 42(2), 205217.

32. Naur, Peter. (2007). Computing versus human thinking. Commun. ACM, 50(1), 85-94. doi: http://doi.acm.org/10.1145/1188913.1188922

33. Neilsen, J. (2009). Guerrilla HCI: Using Discount Usability Engineering to Penetrate the Intimidation Barrier. http://www.useit.com/papers/guerrilla_hci.html

34. Newman, W, \& Taylor, A. (1999). Towards a methodology employing critical parameters to deliver performance improvements in interactive systems. Paper presented at the IFIP TC.13, Amsterday.

35. Nielsen, Jakob. (1993). Usability engineering. Boston: Academic Press.

36. Park, Robert Ezra. (1928). Human migration and the marginal man. The American Journal of Sociology, 33(6).

37. Patterson, D., Brown, A., Broadwell, P., Candea, G., Chen, M., Cutler, J., . . Treuhalf, N. (2002). Recovery-oriented computing (ROC): Motivation, definition, techniques, and case studies Technical report CSD-02-1175. Berkeley, CA: University of California, Berkeley.

38. Power, K. (2010). Stakeholder identification in agile software product development organizations: A model for understanding who and what really counts. Paper presented at the Agile Conference, Orlando, FL.

39. Radle, Karla, \& Young, Sarah. (2001). Partnering Usability with Development: How Three Organizations Succeeded. IEEE Softw., 18(1), 38-45. doi: http://dx.doi.org/10.1109/52.903164

40. Rainer, A., Hall, T., \& Baddoo, N. (2003). Persuading Developers to 'Buy Into' Software Process Improvement: Local Opinion and Empirical Evidence. Proc. Int'l Symp. Empirical Softwware Eng., 326335.

41. Ridgeway, C.I., Johnson, C., \& Diekema, D. (1994). External Status, Legitimacy, and Compliance in Male and Female Groups. Social Forces, 72, 1051-1077. 
42. Rosenbaum, S., Rohn, J.A., \& Humburg, J. (2000). A toolkit for strategic usability: results from workshops, panels, and surveys. Paper presented at the Proceedings of the SIGCHI conference on Human factors in computing systems, The Hague, The Netherlands.

43. Rosenberg, D. (2004). The Myths of Usability ROI. Interactions, 11(5), 22-29.

44. Sen, A.M., \& Hemachandran, K. (2010). Elicitation of goals in requirements engineering using agile methods. Paper presented at the Computer Science and Applications Conference Workshops (COMPSACW), Seoul, Korea.

45. Shneiderman, B. (1980). Software Psychology: Human Factors in Computer and Information Systems. Cambridge, MA: Winthrop.

46. Smilowitz, ED, Darnell, MJ, \& Benson, AE. (1994). Are we overlooking some usability testing methods? A comparison of lab, beta, and forum tests. Behaviour \& Information Technology, 4, 300-303.

47. Stone, Deborah L., Jarrett, C., Woodroffe, M., \& Minocha, S. (2005). User interface design and evaluation. Amsterdam; Boston, Mass.: Elsevier: Morgan Kaufmann.

48. Toigo, J.W. (2008). Key Functions that Define SRM. InformationWeek: The Business Value of Technology. 2009, from http://www.informationweek.com/news/storage/fabrics/showArticle.jhtml?articleID=207800209

49. Tseng, Mitchell M., \& Jianxin Jiao. (1998). Computer-Aided Requirement Management for Product Definition: A Methodology and Implementation. Concurrent Engineering, 6(2), 145-160. doi: $10.1177 / 1063293 \times 9800600205$.

50. US Department of Health and Human Services. (2006). Research-Based Web Design \& Usability Guidelines. 2009, from http://www.usability.gov/pdfs/guidelines.html

51. Velasquez, N. F., \& Weisband, S. P. (2008). Work Practices of System Administrators: Implications for Tool Design. Paper presented at the CHIMIT 2008, San Diego, CA.

52. Wagner, D.G., \& Berger, Joseph. (1997). Gender and Interpersonal Task Behaviors: Status Expectation Accounts. Sociological Perspectives, 40(1), 1-32.

53. Wiegers, K.E. (1999). Software requirements: [practical techniques for gathering and managing requirements throughout the product development cycle]. Redmond, WA: Microsoft Press. 


\section{NOTES}

